\title{
DERECHO ELECTORAL: ASPECTOS JURÍDICOS Y TÉCNICOS
}

\author{
César Landa Arroyo* \\ «El problema consiste en lo siguiente: ¿Cuándo ve- \\ mos al demos actuar como gobernante, o en un pa- \\ pel de gobernante? La respuesta es fácil: en el mo- \\ mento de las elecciones.»
}

Giovanni Sartori

\section{Aspectos juridicopolíticos}

\subsection{Democracia y representación}

La finalidad del régimen democrático radica en el respeto a la libertad del hombre y en controlar al poder. Sin embargo, frente a la imposibilidad de realizar la utopía del autogobierno ciudadano se ha desarrollado la teoría de la representación política, según la cual el pueblo deposita en sus representantes su voluntad popular soberana, asegurando así que todas las personas vivan en sociedad compartiendo reglas de conducta y valores colectivos.

Esos representantes son electos por el pueblo a través de un sistema electoral que contemporáneamente se basa en el derecho de sufragio universal del pueblo, aun cuando, hasta hace muy pocas décadas, el derecho de sufragio se hallaba restringido para los analfabetos, las mujeres y, mucho más antes, para quienes no tenían capacidad económica suficiente, a juicio de la ley. Es pues una tendencia histórica la democratización del derecho de su-

* Este texto ha sido elaborado sobre la base del documento preparado para una exposición ante un grupo de especialistas en materia electoral, realizada en Lima con el auspicio de la Friedrich Ebert Stiftung y la Asociación Civil Transparencia. 
fragio, a fin de que el pueblo ejerza su poder electoral de elegir a sus gobernantes.

No obstante haberse producido un proceso de democratización del derecho electoral, éste apenas ha contribuido a fortalecer la credibilidad del pueblo en la democracia representativa, lo cual se ha puesto en evidencia prácticamente cada vez que se producen golpes de Estado militares o civiles.

Ahora bien, si la soberanía política pertenece al pueblo con capacidad electoral para elegir o cambiar a sus representantes, ello supondría que las potestades de las autoridades electas no son ilimitadas, y que los representantes ejercen sus atribuciones pero no por derecho propio. Sin embargo, una vez que los ciudadanos eligen a sus representantes, éstos se desvinculan de sus electores porque se hacen representantes de toda la nación y no sólo de los sufragantes a favor de ellos.

De allí se coligen tres problemas que aún persisten:

Uno, que como consecuencia de la teoría de la representación nacional no existe mandato imperativo de la población para que su voluntad sea permanentemente obligatoria o consultiva en la toma de decisiones de los representantes al Congreso y del presidente, lo que impide poner en funcionamiento mecanismos de control que puedan llegar eventualmente a la sustitución de la autoridad electa que no responda a la voluntad popular.

Dos, que los representantes sólo quedan supeditados a sus propios límites éticos, claro que flanqueados por la Constitución y las próximas elecciones, por cuanto las autoridades electas no son delegados ni mandatarios de los ciudadanos, sino representantes de la nación, que es una ficción juridicopolítica que reemplaza al pueblo concreto y a sus demandas básicas.

Tres, por consiguiente, el sistema electoral — sin perjuicio del rol de los partidos - ha constituido el soporte jurídico de la desvinculación entre la soberanía popular ciudadana y sus representantes. Si esto es así, el derecho electoral y las técnicas electorales también podrían constituir una pieza clave para cooperar a resolver este divorcio entre soberanía popular y democracia representativa. 
Así, en las democracias avanzadas el derecho electoral tiende a seguir ampliando el derecho de sufragio a través del voto de los transeúntes o por correo (lo cual resuelve el problema del sufragio de los no residentes en el país o en su circunscripción electoral), así como también han extendido el voto a los militares, a los jóvenes mayores de 16 años y a los reos en cárcel; más aún, han hecho del voto un derecho, no una obligación.

Si bien en el Perú no se ha llegado a esos niveles de democratización del derecho de sufragio, en la nueva Constitución de 1993 sí se han consagrado principios que buscan estrechar las relaciones entre el pueblo y sus representantes mediante el reconocimiento de un conjunto de derechos políticos, como la iniciativa legislativa en la formación de las leyes, el referéndum constitucional y legislativo para determinadas materias, así como la remoción de funcionarios y la revocación del mandato de ciertas autoridades (pero que no alcanzan a los reales detentadores del poder estatal - presidente de la República, ministros, congresistas y jefes de los comandos políticomilitares).

En tal sentido, las críticas no siempre marginales sobre nuestra democracia electoral persisten en observar la falta de motivación y participación ciudadana en la vida pública, así como la distancia que se produce entre el Estado y la sociedad, sus autoridades y la ciudadanía, sobre todo cuando el voto ciudadano -que es concebido no como un derecho sino como una obligación- no se traduce en la voluntad soberana del pueblo, sino que sustituyen ésta por la voluntad soberana de la representación.

\subsection{Soberanía popular y derecho electoral}

Sin lugar a dudas un orden legal democrático basado en un sistema electoral debe ser aceptado por todos los participantes, por cuanto no se podría garantizar la vigencia de sus resultados sin el consenso previo entre las fuerzas políticas, consenso que otorga estabilidad a los resultados electorales, además de asegurar un mínimo de seguridad y previsibilidad en las acciones legales y políticas de los electores y los elegibles. Pero también se debería asegurar la participación organizada de la sociedad civil —sin perjuicio del órgano electoral estatal - que con autoridad moral esté por encima de las contingencias electorales y pueda arbitrar los conflictos que se presenten. 
En esta perspectiva, la mayor democratización y modernización del derecho electoral y de sus técnicas pueden servir y sirven a la consolidación o renovación de un sistema electoral transparente e imparcial. En tal sentido, el derecho electoral debe siempre tener en consideración que la voluntad y la educación del pueblo constituyen la causa inicial y objeto final del proceso de democratización. De este modo, se prepara al pueblo en su doble condición de gobernante y gobernado.

En el Perú, como en cualquier otro país, el pueblo se organiza para participar en la vida pública, constituyendo para eso partidos políticos, que son los instrumentos fundamentales, pero no únicos, para el acceso al poder de los ciudadanos. Más aún, en los últimos años la crisis de legitimidad de estas agrupaciones políticas ha dado lugar al surgimiento de liderazgos personales, usualmente sin respaldo institucional, que en la práctica vienen reemplazando a los partidos políticos en las tareas de la orientación y conducción de la vida política y social peruana.

La independencia política, en tal circunstancia, se ha convertido en una conducta electoral relevante, con connotaciones pragmáticas y calificadas por otros de «oportunistas», por cuanto la actitud reflexiva y crítica que caracteriza al independiente en relación a los partidos políticos y a su obra, no tiene necesariamente el correlato de compromiso permanente con los asuntos públicos, o se utiliza la noción de independencia como una forma de soslayar frente a la opinión pública un perfil político tradicional.

Por eso, el derecho electoral y las organizaciones constitucionales -estatales y privadas - comprometidas con el quehacer democrático-electoral, requieren cautelar la auténtica voluntad soberana de todos los ciudadanos del cuerpo electoral, así como comprometer la sana competencia de propuestas electorales entre todas las organizaciones políticas y sus líderes, tanto del gobierno como de la oposición, quienes, además, deberían respetar la dignidad de todos los ciudadanos, del adversario, y someterse a las decisiones de las autoridades electorales.

Pero, junto con introducir la ética de la convicción democrática y, en consecuencia, la ética de la responsabilidad en el propio derecho electoral, la mejor garantía de desarrollar las doctrinas y formas de funcionamiento democráticas está en educar al pueblo con el ejemplo y en cumplir con satisfacer las demandas y expectativas ciudadanas una vez que se llega al go- 
bierno. Ello, pues, debe ser tarea de las entidades estatales y privadas que tienen que ver directamente con la educación, pero, en particular, con la legislación y aplicación de las normas electorales.

Ahora bien, la democratización y transparencia del derecho electoral y de su ejercicio demanda también de un conjunto de técnicas electorales que establecen los cimientos concretos de la democracia electoral y política. Así, definir el cuerpo electoral, el marco territorial de las elecciones, regular el propio desarrollo de las elecciones, así como la recuperación y el procesamiento de los resultados electorales, tiene un impacto directo en la configuración de un régimen político que desee expresar democráticamente la voluntảd popular.

\section{Aspectos tecnicoelectorales}

El presidente de la República, de acuerdo al mandato constitucional, ha convocado, mediante decreto supremo $n .{ }^{\circ}$ 61-94-PCM, a elecciones políticas generales para elegir el próximo 9 de abril de 1995 al nuevo presidente de la República, vicepresidentes y congresistas. Este proceso electoral está regido por la Constitución Política de 1993, la legislación que sobre la materia se ha dictado, como el Texto único integrado del decreto ley $n .^{\circ} 14250$ y la ley orgánica electoral $n .^{\circ} 26337$, aprobado por resolución $n .^{\circ} 043-94-J N E$, así como por la ley $n .^{\circ} 26343$ y la ley $n .^{\circ} 26344$, modificatorias del decreto ley $n .^{\circ} 14250^{*}$.

Es del caso mencionar que en el artículo 177 la Constitución ha consagrado un sistema electoral integrado por el Jurado Nacional de Elecciones (JNE), la Oficina Nacional de Procesos Electorales (ONPE) y el Registro Nacional de Identificación y Estado Civil (RNIEC), que se encargará de conducir el proceso electoral, sin considerar, por cierto, cuál es el organismo rector de dicho sistema.

Sin embargo, lo que es importante dejar planteado es que el Congreso

- Estando este trabajo en imprenta el Congreso ha aprobado la ley $n .^{\circ} 26430$, que norma los actos gubernamentales del ciudadano que ejerza la Presidencia de la República y que postule a la reelección presidencial. 
Constituyente Democrático ha dictado la mencionada ley $n .^{\circ} 26337$, en virtud de la cual ha diferido el funcionamiento de la ONPE y el RNIEC al interpretar discutiblemente la undécima disposición final y transitoria de la Constitución, según la cual «las disposiciones de la Constitución que exijan nuevos o mayores gastos públicos se aplican progresivamente». Este derrotero constitucional restrictivo abre una situación de provisionalidad normativa, por cuanto el JNE se encargará de conducir totalmente el proceso electoral de 1995, asumiendo algunas atribuciones constitucionales que corresponden a la ONPE y al RNIEC. Es decir, el JNE se encuentra sometido parcialmente a la Constitución, debido a que el fundamento último de sus atribuciones se basa en una norma con jerarquía y fuerza de ley.

Esto resulta relevante, no porque conduzca a la nulidad de origen de las elecciones políticas generales de 1995 — como ha sostenido algún jurista-, más aún cuando esa ley de interpretación de la Constitución ha sido aprobada por «consenso» entre la mayoría y las minorías parlamentarias; sino porque coloca al JNE en una relación de imprecisión frente a su rol de directo intérprete constitucional de la legislación electoral, a pesar de que, de acuerdo con el artículo 9 de la ley n. ${ }^{\circ}$ 26303, el Jurado Nacional de Elecciones deberá resolver sobre la aplicación de las leyes durante el próximo proceso electoral según las normas de la Constitución. Es decir, el JNE está facultado legalmente para actuar como un supremo intérprete constitucional, pero sólo en materia electoral.

Ahora bien, en el marco de las circunstancias constitucionales y sobre todo de las disposiciones legales mencionadas, cabe comentar cuatro componentes técnicos del derecho electoral.

\subsection{Cuerpo electoral}

El cuerpo electoral está formado por el conjunto de ciudadanos que tienen derecho a votar y a ser elegidos. La Constitución y la legislación electoral han establecido qué ciudadanos son los que pueden votar y ser elegidos. Así, los mayores de 18 años que gozan de su capacidad civil —es decir, que no son incapaces - tienen el derecho de sufragio. El sufragio, si bien es un derecho, también es un deber, en tanto que es obligatorio hasta los 70 años 
y en caso de incumplimiento corresponde una multa. Luego de los 70 años el voto se convierte en facultativo.

El voto es universal, es decir, es un derecho de todas las personas; pero la propia Constitución ha establecido excępciones específicas y genéricas. Específicas, cuando inhabilita a los policías y militares para gozar del derecho de sufragar y de ser electos. Genéricas, cuando establece que la ciudadanía se suspende por resolución judicial de interdicción, por sentencia con pena privativa de la libertad y sentencia con inhabilitación de los derechos políticos, quedando pues impedidos de votar quienes caigan en estos supuestos.

Por otro lado, junto al derecho de sufragio está el derecho a ser elegido. En este sentido, el derecho electoral tiene ciertas restricciones normativas; por ejemplo, los requisitos para ocupar la Presidencia de la República y las vicepresidencias, además de ser peruano y gozar del derecho de sufragio, comprenden el tener más de 35 años, mientras que para postular al Congreso se debe tener más de 25 años.

Adicionalmente, la ley electoral ha establecido impedimentos para postular a dichos cargos, habiéndose creado un problema constitucional con la pretendida postulación a la Presidencia de la República de la señora Susana Higuchi, esposa del presidente Fujimori, por cuanto la ley electoral establece que los familiares del Presidente, en cuarto grado de consanguinidad y segundo de afinidad - lo cual comprende a su esposa-, no pueden postular a la Presidencia de la República, así como tampoco a las vicepresidencias o a un cargo de congresista, a pesar de que la Constitución no menciona más requisitos que los indicados en el párrafo anterior. Más aún, las únicas inhabilitaciones constitucionales para ser electos recaen en los policías y militares.

Es evidente que frente al histórico presidencialismo peruano, la prohibición a la reelección del presidente y a la elección de sus familiares más próximos — mantenida en las Constituciones de 1933 y 1979 - se garantizó en la ley electoral - decreto ley n. ${ }^{\circ} 14250$ - hoy todavía vigente con algunas modificatorias y ampliatorias. Sin embargo, ante la posibilidad de la reelección presidencial introducida por la actual Constitución, la inhabilitación legislativa de los familiares del presidente de la República resulta 
discriminatoria para el derecho electoral y, en consecuencia, contraria al principio y derecho constitucional a la igualdad ante la ley.

Si bien constitucional y legalmente ha quedado establecido el cuerpo electoral, con las dudas razonables que el JNE tendrá que resolver caso por caso cuando se le presenten, por otro lado, no se puede desconocer que en los últimos procesos electorales se ha puesto en evidencia la falta de participación ciudadana en los procesos electorales, como por ejemplo, el ausentismo de alrededor del treinta por ciento de los ciudadanos registrados para el referéndum constitucional del 31 de octubre de 1993, debido a múltiples razones, entre las cuales se pueden priorizar problemas juridicopolíticos estructurales y coyunturales, como los siguientes:

a) Crisis de motivación ciudadana en el sistema político y en sus representantes, a pesar de la universalización del derecho de sufragio, debido a la falta de ejercicio continuo de los valores cívicos de participación electoral.

b) Crisis de legitimidad del sistema de la democracia representativa, debido a la falta de eficacia y transparencia en la acción política de las organizaciones políticas y de sus líderes.

c) Desplazamiento ciudadano de cerca de seiscientas mil personas de su jurisdicción electoral -alrededor del cinco por ciento de la población electoral- por motivos de violencia política y económica, siendo previsible que un sector considerable de los desplazados sean a su vez indocumentados, es decir, no cuenten con la libreta electoral ni partida de nacimiento.

\section{Alternativas:}

a) Estudiar la incorporación en la ley electoral, como uno de los requisitos para la inscripción de las organizaciones políticas ante el Registro de Partidos del Jurado Nacional de Elecciones, que éstas presenten los lineamientos de un plan o un programa de gobierno que permita a la ciudadanía conocer oficialmente cuáles son las alternativas políticas que pone a debate una organización política para su elección. A su vez, dicho plan o 
programa de gobierno podría tener la calidad de documento de supervisión y control de la opinión pública ciudadana, sobre las acciones de los gobernantes una vez electos.

b) Realizar campañas educativas de concientización cívica de los ciudadanos y de sus derechos electorales, mostrándoles las virtudes de vivir en un régimen democrático, donde tanto los ciudadanos y sobre todo las autoridades del Estado deben someterse a las competencias delimitadas en la Constitución y las leyes, que permiten entonces ser controlados por la población e incluso ser demandados judicialmente en caso de incumplimiento.

c) En función de la magnitud de los desplazados, se debería abrir la posibilidad de instalar «mesas de sufragio de transeúntes involuntarios», con las garantías legales y administrativas que eviten la manipulación o fraude electoral en dichas mesas. En tal sentido, se podrían establecer en las grandes ciudades del país, con fuertes corrientes de inmigración, como Lima que tiene un flujo de 60000 inmigrantes anualmente, registros de transeúntes integrados a la red informática electoral- hasta tres meses antes a la elección, eliminándolos de los padrones electorales de origen, para, luego de la votación, aplicar un sistema de control posterior y al azar sobre posibles casos de doble votación, que daría lugar a una ejemplificadora sanción penal y no sólo pecuniaria.

\subsection{Marco territorial de las elecciones}

El tema del marco territorial de la elección posee una especial importancia, por cuanto condiciona el desarrollo y los resultados electorales, en tanto que las circunscripciones electorales - conocidas también como distritos electorales - se basan en la demarcación territorial — provincial, departamental o nacional.

Es bien sabido que, para 1995, la Constitución ha establecido que todo el territorio del país se constituye en distrito electoral único. Esta circunscripción nacional servirá tanto para la elección unipersonal del presidente y vicepresidentes, como también para los nuevos ciento veinte congresistas. A nivel de las elecciones parlamentarias, el distrito electoral único se utiliza excepcionalmente en las elecciones a Congreso en Israel; sin embargo, ha 
sido un instrumento electoral en los regímenes autoritarios de Salazar en Portugal y Mussolini en Italia.

Ahora bien, los problemas potenciales que presenta el derecho electoral, asumidos para la elección de congresistas y presidente y vicepresidentes, son los siguientes:

a) Establecer que el territorio nacional es un solo distrito electoral supone la elección de representantes en bloque en todo el país; es decir, que la elección se realiza sin asignar un número determinado de plazas de congresistas en función de las circunscripciones electorales provinciales o departamentales. Con lo cual el sistema electoral en sí mismo tiende a no representar los intereses del interior del país; por el contrario, favorece a las organizaciones políticas centralistas y concentradas en la capital de la República, otorgándoles una sobrerrepresentación parlamentaria - por ejemplo, el último Senado electo por distrito electoral único tenía más de un ochenta por ciento de sus miembros que habían sido electos desde Lima.

b) La existencia en el país de más de ciento noventa provincias y mil ochocientos distritos, que sirven de base para la organización de los jurados provinciales y las mesas de sufragio, requiere de la existencia de un organismo electoral que con carácter permanente asuma la función de elaborar el mapa electoral del Estado. Eso supone que el JNE debe constituir una instancia de coordinación estatal con las entidades encargadas de la demarcación territorial, como el Congreso que aprueba por ley la creación de provincias y distritos, sin considerar los criterios técnicos del ordenamiento y demarcación territorial que le corresponde realizar a la Presidencia del Consejo de Ministros, que antes desarrollaba el Instituto Nacional de Planificación y en parte el Instituto Nacional de Informática y Estadística, que se encargaba de registrar la información para efectos catastrales y censales.

c) Como quiera que las provincias y los distritos se crean por ley, el Congreso usualmente modifica la demarcación territorial sin plazo alguno sobre todo en las etapas preelectorales, utilizándolos como prebendas electorales, con argumentos políticos antes que técnicos, lo cual dificulta la organización oportuna de los registros electorales, la reelaboración y eventualmente la distribución de los padrones electorales —cuando un distrito pasa a integrar otra provincia-, la ubicación de las mesas electorales y el conteo posterior en una u otra circunscripción electoral, eventualmente. 
Alternativas:

a) El Jurado Nacional de Elecciones debería ser el organismo encargado de coordinar la elaboración y actualización oportuna de los mapas de demarcación electoral, en función de los plazos de elecciones políticas generales, municipales o regionales establecidos en la Constitución y las leyes, salvo, en cuanto a la periodicidad, cuando se trate de consultas electorales relativas a referéndum, revocación del mandato, entre otras actividades de índole electoral.

b) El Jurado Nacional de Elecciones debería coordinar estrechamente con el Congreso, para establecer un plazo límite prudencial después del cual no se deban crear por ley nuevos distritos y provincias hasta pasadas las elecciones, salvo que la nueva demarcación territorial no sea considerada para las elecciones inmediatas siguientes. Así, por ejemplo, con la convocatoria a elecciones el Congreso ya no debería aprobar la creación de distritos, provincias o regiones.

c) Estudiar la realización de elecciones políticas sobre la base de circunscripciones electorales múltiples - regionales, departamentales, provinciales-, sin necesidad de condicionarla a la finalización del proceso de descentralización, asegurando así la elección de circunscripciones y/o categorías electorales que representen los intereses y necesidades de las localidades del interior del país.

\subsection{Organización de las elecciones}

La regulación adecuada de la participación ciudadana para las elecciones en un marco territorial representativo, aun siendo muy importante, no garantiza del todo el carácter democrático de una elección si es que no se cuenta con un Registro Electoral Nacional actualizado; muestra de ello es que, para la votación del referéndum constitucional de 1993, la renovación o actualización de los padrones electorales estaban efectuadas sólo hasta 1991. Es decir, no se contó con un padrón electoral cien por ciento confiable.

Las causas fundamentales del uso de padrones electorales desactualizados se encuentran en que: 
a) En el Padrón Electoral Nacional figuran usualmente los nombres de personas que han fallecido, que están interdictas, que están en prisión como condenadas e incluso tan sólo en calidad de detenidas mientras «demora» el proceso judicial. Así, de los cerca de veinte mil internos que se encuentran en los penales, 14506 están en calidad de procesados.

Asimismo, se registra como sufragantes a personas que ya no residen en un distrito, debido a que no existe una práctica ciudadana de inscribir en el registro electoral distrital los cambios domiciliarios voluntarios e involuntarios (en este último caso, de los desplazados y refugiados económi$\cos$ ), lo cual da lugar, en consecuencia, a padrones electorales que no corresponden a la realidad. Adicionalmente, no obstante que la Constitución y las leyes prohíben a los miembros de la Policía Nacional y de las Fuerzas Armadas ejercer derechos políticos, por motivos de seguridad decenas de miles de ellos se han inscrito en el registro electoral, obteniendo en consecuencia una libreta electoral, documento reservado únicamente para quienes tienen derecho de sufragio.

b) Existe un conjunto de personas que no figuran en los padrones electorales por estar «indocumentadas». Unas, son aquellas personas que no están inscritas en el registro electoral, es decir, que no cuentan con libreta electoral por razones tan diversas como realidades en el país; por ejemplo: desinformación, falta de reparticiones públicas registrales en las zonas rurales - amazónicas y andinas - o alejadas de los pueblos y caseríos. Otras, no cuentan ni siquiera con su partida de nacimiento, requisito indispensable para obtener la libreta electoral. Finalmente, una explicación residual de la existencia de «indocumentados» es la falta de motivación o desconfianza de las personas para incorporarse al sistema de identificación legal de las mismas.

c) Es sobre la base de esa información desactualizada y parcial que los registros electorales distritales y sobre todo provinciales remiten al $\mathrm{Re}$ gistro Electoral Nacional la nómina formal de los inscritos, para que éste confeccione los listados electorales de cada mesa de sufragio, para lo cual ha contado en los últimos tres procesos electorales con el apoyo informático de la compañía IBM del Perú.

Ciertamente que, una vez elaborados estos padrones, no existe un con- 
trol o verificación posterior de los mismos, no sólo por la depuración eventual de los listados que deberían realizar los registros electorales provinciales -donde se han inscrito los ciudadanos- sino también por las probables inconsistencias o errores en la confección informatizada de los padrones que se han detectado en la última votación, con la consiguiente remisión de padrones electorales correspondientes de una circunscripción electoral a otra.

\section{Alternativas:}

a) El Jurado Nacional de Elecciones y el Registro Nacional Electoral deberían coordinar las acciones administrativas necesarias que permitan contar en cada elección con un padrón electoral actualizado, dictando para tal efecto las disposiciones reglamentarias que faciliten la obtención de la libreta electoral y permitan la regularización de la inscripción registral de los desplazados y migrantes, incorporándolos al padrón electoral de la circunscripción de su residencia real. Asimismo, se debería exonerar de la multa a los ciudadanos que por estar detenidos en las prisiones no pueden votar y abrir un registro especial para los policías y militares a fin de que obtengan una libreta electoral sin necesidad de figurar en el padrón electoral, en caso de seguridad personal.

b) La elaboración de los padrones electorales debería descentralizarse. Es decir, deberían ser elaborados e impresos desconcentradamente por los registros provinciales, por delegación del RNE, contando para el efecto con la asesoría técnica correspondiente y el sistema de cómputo existente para el conteo electoral en los jurados electorales ahora provinciales. El Registro Nacional sería el organismo nacional encargado de supervisar técnicamente la elaboración de los padrones electorales, accediendo directamente a la información registral mediante la red computarizada.

c) Promover una campaña de información y educación cívica para que las personas obtengan sus partidas de nacimiento y se inscriban en los registros electorales, y promover previamente, así como también realizar, campañas de sensibilización y moralización de los empleados públicos encargados de extender dichos documentos. Asimismo, se deberían establecer instancias o comités de coordinación permanente entre el sistema del Registro Electoral Nacional y las autoridades del Sector Salud, la Policía Nacio- 
nal y las municipalidades, para que se informe periódicamente a los registros electorales correspondientes, de los partes, certificados y actas de defunción que expiden sus dependencias, a efectos de depurar periódicamente los registros electorales y exigir la devolución de la libreta electoral en los casos en que se registren decesos.

\subsection{Desarrollo y resultado de las elecciones}

El acto electoral se concreta en el sufragio de los electores, la oportuna resolución de los problemas de aplicación de las normas electorales, la obtención de los resultados y la proclamación de los candidatos electos. Esto supone que la inscripción de las organizaciones políticas y de sus candidatos, el despliegue del material electoral y el repliegue del mismo, la transferencia ágil y confiable de los resultados electorales, así como la transparencia del mismo acto electoral, estén acordes a las reglas de veracidad y oportunidad de la voluntad popular.

Sin embargo, este principio de transparencia de la voluntad popular ha sido puesto a debate indirectamente, en razón a una serie de dificultades que se han hecho patentes en los procesos electorales inmediatamente anteriores, tanto por parte de los candidatos y ciertos medios de comunicación social, como por parte de las encuestadoras de opinión; poniendo en evidencia un uso indiscriminado de recursos impugnatorios de las decisiones electorales, un uso éticamente discutible de los recursos económicos de las empresas y del Estado, así como un uso de cierto tráfico de influencias - públicas y privadas- en las campañas publicitarias electorales.

De otro lado, en el actual proceso electoral las reiteradas modificaciones legislativas de las reglas de juego electorales, como la reprogramación del calendario electoral aprobado por el JNE y la incorporación de la foto de los candidatos en las cédulas de sufragio, cuando sólo el candidato-presidente Fujimori ha sido quien ha utilizado la estrategia electoral de regalar afiches con su imagen desde antes del inicio del proceso electoral, constituyen manifestación de serias irregularidades que afectan la transparencia del proceso electoral.

Pero la eficiencia del proceso electoral también se ha puesto en cues- 
tión por parte del JNE en los procesos electorales anteriores, por la demora en la toma de decisiones electorales, tanto en las etapas preelectoral y postelectoral, lo cual ha dado lugar a que los poderes privados mencionados -medios de comunicación y encuestadoras de opinión- se constituyan en los voceros cuasi-oficiales - sobre todo de los resultados electorales- pero sin la garantía de la autonomía y protección del interés general que sólo está asegurado por el Estado a través del JNE.

Algunas causas de este proceso de privatización de los procesos electorales se encuentran en:

a) Las empresas encuestadoras en la última década han ido apareciendo, a través de los medios de comunicación social, como las entidades técnicamente autorizadas para medir la voluntad electoral ciudadana, sin considerar que muchas veces administran, incluso, dicha voluntad, en una población con un bajo nivel cultural y de identidad electoral. La disposición legal que permite la difusión de la encuestas electorales sólo hasta quince días antes de la elección, tan sólo es una medida paliativa para abordar el problema planteado.

b) Los miembros de los jurados electorales, así como los personeros legales de las organizaciones políticas y, sobre todo, los miembros de las mesas de sufragio, no están formados en el derecho electoral ni capacitados en las técnicas electorales. Además, las autoridades electorales asumen directa y centralizadamente responsabilidades en asuntos administrativos y gerenciales (como en materia de abastecimiento, informática, racionalización, diseño gráfico, publicidad electoral, etc.) que tienen técnicas ajenas a su formación o ejercicio profesional de jueces, fiscales o abogados, básicamente.

c) Los personeros legales inician procesos contenciosos electorales mediante impugnaciones, tachas o nulidades, tanto en la etapa preelectoral de inscripción de los partidos, organizaciones políticas, candidaturas, símbolos, etc., como en la etapa postelectoral de recojo de los resultados electorales, algunas veces sin fundamentos jurídicos sólidos y otras veces sólo para restar votos a los contrincantes - sobre todo en el conteo del voto preferencial para los candidatos al Congreso-, siendo tramitados dichos procesos engorrosamente por las autoridades electorales, como si fueran otros tantos procesos judiciales. 
d) La absolución de las consultas y las incidencias que se producen durante el día del sufragio electoral, quedan libradas a las decisiones de los presidentes de las mesas de sufragio, las cuales no siempre se encuentran acordes con el derecho electoral. Esto da lugar a que los personeros planteen impugnaciones y nulidades de actas electorales; por ejemplo, porque todos los miembros de la mesa de sufragio no las firmaron, porque registraron el número de cédulas como el número de votos, porque introdujeron los sobres con los resultados electorales en el ánfora, entre otras razones.

Esta situación se hace más crítica en las zonas bajo estado de emergencia —alrededor del treinta por ciento del territorio del país, el cual abarca casi el cincuenta por ciento de la población-, donde la autoridad de los comandos político-militares y/o la autoridad militar responsable de la seguridad del centro de votación, es quien arbitra o decide en muchos conflictos electorales sobre la campaña electoral y la votación, respectivamente. De modo que la seguridad y la logística que prestan básicamente las autoridades militares las ubica en una posición preferente, posición que no se subordina a las autoridades electorales.

e) Se presentan dificultades y demoras para la instalación de los jurados electorales, incluido el JNE, debido a la adquisición de inmuebles, bienes y servicios (como la instalación de los sistemas de comunicación y cómputo). Existe también falta de coordinación oportuna para la implementación adecuada de las mesas de sufragio con el material electoral correspondiente. En particular, están sumamente centralizadas las decisiones de ejecución de los planes de distribución y recuperación del material electoral a cargo de las Fuerzas Armadas, sin la debida consulta a los organismos electorales locales responsables de conducir el proceso electoral, sobre todo en las zonas marginales del país.

\section{Alternativas:}

a) Capacitar oportunamente al personal de los jurados provinciales electorales y sobre todo a los miembros de las mesas de sufragio, en el derecho y las técnicas electorales, promoviendo la simplificación administrativa, la resolución de los procesos contenciosos electorales bajo principios procesales ejecutivos y con capacidad resolutiva sumaria por parte de la au- 
toridad electoral -incluso bajo responsabilidad-, sin perjuicio de garantizar los derechos de los sufragantes y candidatos.

b) Renovar a los integrantes de las mesas de sufragio y convocarlos con una anticipación mayor a la usual. Asimismo, incentivar la participación ciudadana de los alumnos de los últimos años de estudios universitarios, tanto para capacitar a los miembros de las mesas electorales y jurados provinciales, estableciendo sistemas compensatorios en créditos -como en el último censo nacional de población - o considerando el doble de tiempo que deben realizar en el Servicio Civil de Graduandos en Derecho (SECIGRA-DERECHO) por el tiempo que han prestado apoyo como capacitadores electorales, como también ejerciendo la función de «orientador electoral» en cada centro de sufragio - que son alrededor de dos mil en Lima - durante el día de la votación, para absolver las consultas de los miembros de mesa, personeros y sufragantes.

c) El Jurado Nacional de Elecciones debería ser el ente rector de un sistema de planificación electoral, creando para el efecto un organismo especializado encargado de conducir autónoma y técnicamente los procesos electorales en cuanto al diseño, ejecución y supervisión de los planes y programas de elaboración, envío y repliegue del material electoral y los resultados electorales.

d) El Jurado Nacional de Elecciones debería crear un registro de las empresas especializadas en realizar encuestas electorales de opinión pública, en el cual periódicamente dichas empresas deberían registrar los datos constitutivos de las encuestas que realizan: el universo de la encuesta, lugares donde se aplicó, todas las preguntas formuladas y las respuestas obtenidas, los nombres de quienes las solicitan y financian. La publicidad de la ficha técnica, junto con los resultados, sería un deber de las encuestadoras y un derecho de cualquier ciudadano para acceder al registro que para el efecto crearía el JNE.

e) El JNE debería promover que los candidatos o sus personeros legales suscriban un pacto ético-electoral, como el Pacto de San Marcos, en el cual se comprometan a no abusar del derecho y de sus vacíos, y a respetar las normas de la contienda electoral en el marco de la veracidad y simplificación de los recursos impugnatorios que sean estrictamente necesarios. Asimismo, en virtud de dicho pacto, se deberían comprometer a hacer un 
uso razonable y equitativo de los recursos y vínculos económicos para la publicidad electoral.

En todo caso, los graves conflictos electorales que surjan antes, durante y después de la votación, entre las organizaciones políticas en contienda, podrían ser puestos a consideración consultiva de una institución arbitral de la sociedad civil, para eventualmente buscar la conciliación pronta y equitativa, o en todo caso conocer la opinión que sobre el conflicto se expida a pedido de los interesados. 


\section{Bibliografía}

ARNALDO ALCUBILLA, Enrique

1993 «Las competencias de la Junta Electoral Central», Derecho electoral, Consejo General del Poder Judicial, Madrid.

DUVERGER, Maurice, y Giovanni SARTORI

1988 «Los sistemas electorales», Cuadernos de CAPEL, 27, Centro Interamericano de Asesoría y Promoción Electoral, Costa Rica.

ESTEBAN, Jorge de, et. al.

1977 El proceso electoral, Politeia, Madrid.

GARCÍA BELAUNDE, Domingo

1986 Una democracia en transición. Las elecciones peruanas de 1985, Okura, Lima.

HERNÁNDEZ BECERRA, Augusto

1988 Derecho electoral. La elección popular de alcaldes, Universidad Externado de Colombia, Bogotá.

INSTITUTO INTERAMERICANO DE DERECHOS HUMANOS

1988 Diccionario electoral, CAPEL, San José de Costa Rica.

JURADO NACIONAL DE ELECCIONES

1990 Legislación que regirá en el proceso electoral 1990, publicación oficial, Lima.

LANDA ARROYO, César, y Ana VELAZCO LOZADA

1994 Constitución Política del Perú 1993, Maestría en Derecho con mención en Derecho Constitucional, de la Pontificia Universidad Católica del Perú, Lima. 
190 DERECHO 48/1994 - Facultad de Derecho de la Pontificia Universidad Católica del Perú

PANIAGUA CORAZAO, Valentín

1993 «Sistema electoral», La Constitución de 1993. Análisis y comentarios, CAJ, Lima.

PAREJA PFLUCKER, Piedad, y Aldo GATTI MURRIEL

1993 Elecciones municipales en las provincias de Lima y el Callao, Fundación Friedrich Ebert, Lima.

PÉREZ SERRANO, Nicolás

1984 Tratado de Derecho político, Civitas, Madrid. 